Research Paper:

\title{
Investigating the Psychometric Properties of the Psychological Virtue of Courage Scale Among University Students
}

\author{
Leila Habib Allah Nataj ${ }^{1}$, Bahram Mirzaian ${ }^{1 *}{ }^{*}$ Mohsen Jadidi $^{2}$
}

1. Department of Psychology, Sari Branch, Islamic Azad University, Sari, Iran.

2. Department of Clinical Psychology, Bandar Gaz Branch, Islamic Azad University, Iran.

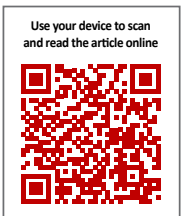

Citation Habib Allah Nataj L, MirzaianB, Jadidi M. Investigating the Psychometric Properties of the Psychological Virtue of Courage Scale Among University Students. Avicenna J of Neuropsychophysiology. 2019; 6(1):45-52. http://dx.doi.org/10.32598/ajnpp.6.1.60

http://dx.doi.org/10.32598/ajnpp.6.1.60

\section{() 03}

Article info:

Received: 02 Sep 2018

Accepted: 26 Dec 2018

Available Online: 01 Feb 2019

Keywords:

Psychometrics, Courage,

Virtues, Quality of life

\begin{abstract}
A B STRACT
Introduction: Positive psychology, as a new domain of psychology, is focused on understanding and describing happiness and mental wellbeing and predicting their associated factors.

Objectives: The present study aimed to investigate the psychometric properties of the virtue of courage scale and its relationship with social health and life quality among university students.

Materials and Methods: The research method was based on tool construction and development. The statistical population consisted of 10221 students of the Islamic Azad University of Sari Branch in the 2017-2018 academic year. Of whom, a sample of 384 subjects was selected. The required data were collected by a researcher-made questionnaire of psychological courage regarding Islamic scholars 'views, the 26-item World Health Organization Quality of Life (WHOQOL-26) questionnaire, and the Keyes Social Health Questionnaire. Nonparametric Spearman's rank-order correlation and multiple linear regression methods were used to determine the relationships between the items. The scale's content validity was assessed by the Content Validity Index (CVI) and Content Validity Ratio (CVR) indices based on Leo's Table. SPSS was used for data analysis.
\end{abstract}

Results: The obtained results suggested that the value of the first factor equaled 5.47; therefore, it was a significant factor in factor analysis. In total, 7 factors explained $60.10 \%$ of the variance. The correlation coefficients between the subscales and the total score of courage, quality of life, and social health scales indicated a proper concurrent validity of the courage scale. To investigate the validity of the 31-item scale, internal consistency (Cronbach's alpha coefficient) was calculated, ranging from 0.83 to 0.93 .

Conclusion: The psychometric properties of the psychological virtue of courage scale have been supported; thus, it could be used in future research studies. Additionally, there was a significant relationship between courage, quality of life, and social health in this inventory.

\section{* Corresponding Author:}




\section{Introduction}



ositive psychology, as a new domain of psychology, is focused on understanding and describing happiness and mental wellbeing and predicting factors affecting these components [1]. Positive psychology is concerned with character strengths and character virtues. Virtue is defined as any psychological process that consistently enables a person to think and act to obtain individual and social benefits [2]. Character strengths are also psychological components or processes associated with the rejection and promotion of the virtues; they reflect the ways to achieve the merits [3]. Patterson and Seligman discussed hierarchical personality traits and introduced positive psychological character strengths; they include 6 virtues and 24 particular character strengths. Each of the 6 virtues consists of a set of trait strengths [3]. The 6 virtues considered in the values of the classification system of practice are wisdom, courage, humanity, justice, temperance, and transcendence [4].

One of these virtues that have been emphasized is the virtue of courage. Psychologically, courage is defined as "mental energy involved in coping with destructive habits, worries, and irrational fears along with seeking the truth in daily life." Courageous actions alone are not sufficient; they require emotional and cognitive skills and the essential steps before demonstrating bold actions. Besides, autonomous motivation is necessary to develop positive emotional skills to reduce fear correlations [5].

Various studies have examined individuals' experiences of the emotional, cognitive, and situational effects of courageous actions in daily life. Studies on positive psychology indicated that the interventions based on the strengths could enhance the sense of wellbeing and Quality of Life (QoL). This is because of the internalized motivational factors that elicit individuals' actual values, intentions, and interests [6, 7]. Furthermore, data on the effects of positive emotional refocusing on motivation, attitudes, and behavior change in the long run are limited. Consequently, the evidence that supports whether autonomously supportive influences, like life coaching, could significantly affect individuals' internalization process, psychological courage, wellbeing, and QoL is scarce, especially in the nonclinical population [8].

Research on virtues and character strengths has been increasing over the past decade [9]. Thus, various studies have explored positive psychology in terms of virtues and character strengths [10]. These studies reported that all character virtues have a negative relationship with neuroticism and a positive relationship with openness to experience, extraversion, and conscientiousness [11]. Regarding the virtues, moderation was correlated with conscientiousness, and courage was correlated with emotional stability. Besides, character strengths also enable people to perform better and have a satisfying and enjoyable life [12]. These strengths are associated with psychological wellbeing, academic achievement, school regulation, academic performance, and life satisfaction [13].

Character strengths and virtues determine how humans cope with difficulties. Therefore, character strengths must be directly related to coping behaviors and protect individuals from the adverse effects of work-related stress. Prior research has indicated that character strengths play a protective role in coping with stress and life pressures [14]. The application and development of these empowering strengths also facilitate the experience of positive emotions, which, in turn, prepare one to cope with daily stressors [15]. Darabi, McAskill, and Reildy examined the relationship between stress and coping styles with religious divine character strengths (related to the virtue of transcendence). They found that three divine religious strengths, namely hope, optimism, and gratitude, were negatively correlated with stress [16]. Moreover, Duan, Ho, Siu, Lee, and Zhang argued that all 6 personality virtues that Peterson and Seligman introduced were negatively correlated with stress perception [17]. Harzer and Rush reported that character strengths are related to coping with job stress. They found that interpersonal, cognitive, and emotional strengths significantly affect nurses' coping with their job stress [18].

Gender et al. also examined the role of character strengths in identifying healthy and unhealthy styles of coping with job stress. They found that the strengths profile of individuals with healthy coping styles for job stress was significantly different from those with unhealthy patterns [19]. Arns and Joseph Morgan also examined the character strengths of gratitude, and they called it the antidote to job stress [20]. Besides, Avy et al. investigated 974 employees from several organizations. They concluded that cognitive strengths (related to the virtue of wisdom and knowledge) had a significant negative relationship with job stress. Therefore, the present study aimed to investigate the psychometric properties of the Psychological Virtue of Courage Scale and its relationship with social health and QoL among university students [21]. 


\section{Materials and Methods}

The research method was based on tool construction and development. The statistical population consisted of 10221 students of the Islamic Azad University of Sari Branch in the 2017-2018 academic year. Of them, a sample of 384 subjects was selected by convenience sampling method. To determine the sample size, 10 observations (10 persons) were considered for each question. These guidelines are typically stated in terms of either the minimum necessary sample size, the total sample $(N)$, or the minimum ratio of $\mathrm{N}$ to the number of variables being analyzed [22]. To consider the ethical principles, first, some explanations were provided to the study participants about the subjects, purposes, and instructions to complete the questionnaires.

The study inclusion criteria included the age range of 20-45 years, being a university student, and having personal consent to fill the questionnaire. The exclusion criteria included providing incomplete questionnaires, aged under 20 or over 45 years, and not being a university student. The ethical considerations of the present study were as follows: all individuals received written information about the research, and they participated in the study voluntarily. They were ensured that all their data would remain confidential and only used for research purposes. For respecting others' privacy, the study participant's name and surname were not recorded.

A researcher-made questionnaire of psychological courage regarding Islamic scholars' views was developed. The Psychological Virtue of Courage Scale based on Islamic scholars' views had no background; thus, it has been designed and developed for the first time by a researcher to measure the virtue of courage based on Islamic philosophy sources. The developing process of this scale was as follows. To identify the items related to the psychological virtues of courage, according to Islamic scholars' views, an in-depth study of the sources of Islamic philosophy was conducted, and various documents were reviewed. Then, the initial design of the questionnaire was developed based on 72 items regarding the concepts and documents. To assess the content validity of the questionnaire, 10 experts were requested to assess the necessity and relevance of the items. Following the experts' views, 20 out of 72 items were removed due to irrelevance. After verifying the content validity of the questionnaire, to test its reliability, a 52 item questionnaire of virtue of courage was distributed among 50 subjects. The reliability of the questionnaire was measured as 0.88 based on Cronbach's alpha coef- ficient. Next, the questionnaire's items were reduced from 52 to 44 . The questionnaire was restricted to 31 items after conducting Exploratory Factor Analysis (EFA) (on 384 subjects). Then, the questionnaire's validity was examined based on a panel of 5 experts. Its content validity was approved and 7 dimensions were measured with Cronbach's alpha coefficient (endurance: 0.83, stability: 0.82 , perseverance: 0.79 , patience: 0.72 decisiveness: 0.75 , persistence: 0.73 , and continence: 0.85 ); while 7 extracted dimensions explained $60.10 \%$ of the courage variance. A 5-point Likert-type scale and 10 inverse items were included in the questionnaire.

The 26-Item World Health Organization Quality of Life (WHOQOL-26): This scale was developed in 1996 by a team of WHO experts. The questionnaire consists of 26 questions in 4 dimensions; it is evaluated based on a 5-point scale, used as a comprehensive scale. This scale includes QoL and general health levels. Cronbach's alpha coefficient of the Persian version of the questionnaire was obtained as 0.70 for physical health, 0.73 for psychological health, 0.55 for social relations, and 0.84 for environmental ties [23]. In this study, Cronbach's alpha coefficient used to examine a 50-item questionnaire; physical health was scored as 0.85 , psychological relation: 0.78 , social relations: 0.75 , environmental relations: 0.71 , and finally, the overall QoL was scored as 0.89 .

Keyes Social Health Questionnaire: This questionnaire was developed in 2004, and it has 33 items and 5 dimensions (social integration, social acceptance, social contribution, social actualization, and social coherence), i.e. measured based on a Likert-type scale. The lowest possible score in social health was zero, and the highest possible score was 132 . The validity and reliability of this questionnaire have been confirmed in Iranian studies. The questionnaire's validity investigations suggested a Cronbach's alpha coefficient measured as 0.81, 0.77, $0.82,0.69,0.77$, and 0.70 for social integration, social acceptance, social contribution, social actualization, and social coherence, respectively [24]. In this study, based on a 50-item questionnaire, Cronbach's alpha coefficient was measured to be 0.84 for social integration, 0.71 for social acceptance, 0.88 for social contribution, 0.79 for social actualization, 0.87 for social cohesion, and 0.91 for the overall health instrument.

SPSS was used for data analysis. Regarding the normality assumption under the Kolmogorov-Smirnov test and calculating skewness and kurtosis for the score of variables, there were no multiple linear regression preconditions. Therefore, nonparametric Spearman's rankorder correlation and multiple linear regression meth- 
ods were used to determine the relationships between the items. Content validity was assessed by the Content Validity Index (CVI) and Content Validity Ratio (CVR) indices based on Leo's Table. The significance level was considered at 0.01 .

Both CVR and CVI were used to quantitatively examine the content validity. The CVI was calculated as the cumulate score for each item under the following titles; "relevant but needs a review" and "completely relevant" points divided by the total number of the experts. To determine the CVR, the experts were required to rank each item based on three ranges; "necessary," "useful but not necessary," and "not necessary." If the calculated value was higher than the table value, the item's content validity was confirmed.

\section{Results}

The studied sample consisted of 249 (64.8\%) females and 135 (35.2\%) males; while 97 (25.3\%)of them were college students, 171 (44.5\%) of them were undergraduate students, 67 (17.4\%) of them were postgraduate students, and 49 (12.8\%) of them were Ph.D. students. The mean(SD) score of the respondents' age was 25.5(6.6) years.

To examine the courage virtue, 72 questions were extracted from the literature review, some of which were conceptually similar; thus, in the first step after consulting with 20 experts, the questions' necessity and relative frequency were determined based on points 4 and 5 and IS coefficient for 72 items. Regarding the answers to each question, the IS coefficients with 1.5 were compared. Accordingly, in 20 items, the IS value was $<1.5$ (question number: 5-6-10-14-20-21-30-3236-38-39-40-42-43-44-45-46-57-62-65); thus, they were inadequate, and the questions were consequently removed from the questionnaire. In the second step, regarding a 10-person content validity panel, the CVR was calculated based on the necessity, and the CVI and the relevance of the questions were assessed. The CVI of the questionnaire was scored as 0.866 , and compared with the standard value of 0.79 , its content validity was confirmed. Moreover, regarding the CVR values, 8 questions were removed (questions number 5-12-18-21-2832-39-44). The item values based on Lawshe Table with a 10 -person panel were calculated as $<0.62$.

In this stage, the questionnaire was reduced from 52 to 44 questions. Next, the questionnaire's reliability was assessed based on a 50-item sample of the target population, and 8 items $[15,16,20,23]$ were removed to improve the Cronbach's alpha coefficient level; accordingly, this value was improved from 0.867 to 0.899 . The questionnaire was reduced to 34 questions. In EFA, according to the value of the Kaiser-Meyer-Olkin (KMO) test and the significance of Bartlett's test, performing EFA was possible. In the first examination, 9 components were extracted. Then, they were removed following varimax rotation, and the questions were eliminated due to a factor load $<0.4$ and a negative load as well as those with only one question that could not be cumulated. This was considered when two components had only one question and in item 13 , where the factor load was scored as $<0.4$. After eliminating the three related questions, eventually, the number of items was reduced to 31 questions, and 7 components were extracted. Therefore, endurance had 4 items, and stability had 7 questions; patience had 54 items; perseverance had 7 questions, decisiveness had 5 questions; persistence had 4 questions, and continence had three questions. The obtained results are explained below.

Table 1. Final statistical characteristics based on three-factor processing (varimax rotation) with eigenvalues $>1$

\begin{tabular}{cccc}
\hline Components & Eigenvalues & The Proportion of Variance Explained & Cumulative Percentage Variance \\
\hline 1 & 5.47 & 17.65 & 17.65 \\
\hline 2 & 2.89 & 9.32 & 26.98 \\
\hline 3 & 2.56 & 8.26 & 35.25 \\
\hline 4 & 2.31 & 7.48 & 42.73 \\
\hline 5 & 1.94 & 6.28 & 49.02 \\
\hline 6 & 1.82 & 5.87 & 54.89 \\
7 & 1.61 & 5.21 & 60.10 \\
\hline
\end{tabular}


Table 2. The concurrent validity of courage and its relation to its dimensions with QoL and social health scales

\begin{tabular}{|c|c|c|c|c|c|c|c|c|c|}
\hline & Variabels & Endurance & Stability & Decisiveness & Courage & Patience & Continence & Persistence & Bravery \\
\hline \multirow{5}{*}{ 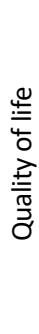 } & Physical domain & 0.29 & 0.24 & 0.25 & 0.21 & 0.32 & 0.24 & 0.14 & 0.46 \\
\hline & $\begin{array}{l}\text { Psychological } \\
\text { domain }\end{array}$ & 0.40 & 0.26 & 0.35 & 0.30 & 0.36 & 0.31 & 0.20 & 0.58 \\
\hline & $\begin{array}{l}\text { Community Rela- } \\
\text { tions }\end{array}$ & 0.45 & 0.32 & 0.36 & 0.30 & 0.34 & 0.27 & 0.23 & 0.63 \\
\hline & $\begin{array}{l}\text { Environmental } \\
\text { domain }\end{array}$ & 0.33 & 0.25 & 0.38 & 0.26 & 0.31 & 0.24 & 0.18 & 0.54 \\
\hline & Total QoL & 0.41 & 0.30 & 0.36 & 0.36 & 0.29 & 0.23 & 0.22 & 0.61 \\
\hline \multirow{6}{*}{ 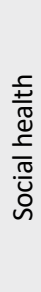 } & Social solidarity & 0.67 & 0.49 & 0.58 & 0.45 & 0.55 & 0.44 & 0.37 & 0.99 \\
\hline & Social acceptance & 0.52 & 0.34 & 0.41 & 0.36 & 0.41 & 0.36 & 0.29 & 0.77 \\
\hline & Social participation & 0.49 & 0.35 & 0.48 & 0.38 & 0.41 & 0.33 & 0.30 & 0.77 \\
\hline & Social adaptation & 0.45 & 0.33 & 0.39 & 0.36 & 0.36 & 0.35 & 0.20 & 0.70 \\
\hline & Social prosperity & 0.55 & 0.38 & 0.46 & 0.33 & 0.42 & 0.36 & 0.32 & 0.81 \\
\hline & Social health & 0.48 & 0.36 & 0.43 & 0.35 & 0.36 & 0.33 & 0.21 & 0.74 \\
\hline
\end{tabular}

The principal component analysis with varimax rotation at the item level was used to investigate the scale's factor structure (validity). The sampling adequacy test results indicated that the sample was suitable for factor analysis (KMO=0.79). Moreover, Bartlett's Spearman test with a degree of freedom (df) of 465, and approximate Chi-squared $\left(\chi^{2}=4472.26\right)$ was significant at $\mathrm{P}<0.0001$; therefore, factor analysis could be reported. The pebble diagram and values of eigenvalues $>1$ suggested that the 7 extracted factors cumulatively explained $60.88 \%$ of the variance.

As per Table 1, after the varimax rotation, the value of the first factor equaled 5.47; therefore, it was a major factor in factor analysis. In total, 7 factors explained $60.10 \%$ of the variance. The factor loadings matrix revealed that all the extracted factor loadings were $>0.40$, and the distribution of items in the subscales corresponded to the original test. The scale's criterion validity was assessed through concurrent validity (the concurrent implemen- tation of QoL and social health scales). The correlations of the subscales were also calculated (Table 2).

The correlation coefficients between the subscales and the total score of courage, QoL, and social health scales indicated a proper concurrent validity of the courage scale. To investigate the validity of the 31-item scale, internal consistency (Cronbach's alpha coefficient) was calculated (Table 3). The retest method was also used to examine the stability of the questionnaire. For this purpose, 50 study participants responded to the scale questions in a 10-day interval, and Pearson's correlation coefficient of the questionnaire scores was calculated in two replications. The number of items, the Cronbach's alpha coefficient, and retest values, as well as every three components, are listed in Table 3. All retest coefficients were significant.

Table 3. Cronbach's alpha Coefficients and retest values of courage components

\begin{tabular}{|c|c|c|c|c|}
\hline \multirow{2}{*}{ Components } & \multicolumn{2}{|c|}{ Cronbach's Alpha } & \multirow{2}{*}{ Total } & \multirow{2}{*}{$\begin{array}{l}\text { Test-Retes } \\
\text { Coefficien }\end{array}$} \\
\hline & Male & Female & & \\
\hline Perseverance & 0.85 & 0.80 & 0.83 & 0.70 \\
\hline Transcendental communication and understanding & 0.81 & 0.80 & 0.83 & 0.66 \\
\hline Presence of God and receiving spiritual support & 0.75 & 0.64 & 0.93 & 0.73 \\
\hline Total & 0.86 & 0.60 & 0.93 & 0.78 \\
\hline
\end{tabular}




\section{Discussion}

The collected data suggested that the questionnaire of the psychological virtue of courage has 7 components. There was a correlation between the subscales and the total score of courage, QoL, and social health scales, indicating a proper concurrent validity of the courage scale. The obtained results indicated that this research instrument benefits from high general reliability as well as high reliability for each subscale. Thus, the 31-item researcher-made questionnaire was presented as a research instrument with desirable reliability and validity. These results were consistent with those of Shojaei's study in which he examined the basis of traits psychology in ethics. His observations revealed that the explanation of personality based on characteristics had long been a dominant approach in the field of ethics. Mainly, considerable conversion and similarity existed between the traits theory and Islamic scholars' views; this trend has been continued by Islamic scholars over the years. Since the traits theory and the views of scientists are similar, we could refer to these implicit theories of traits [19]. These findings were in line with those of an earlier study [8]; it was found that regarding the virtues, moderation was correlated with conscientiousness, and courage was correlated with emotional stability [8]. Character strengths also enable individuals to perform better and to have a satisfying life quality [9]. These strengths are associated with psychological wellbeing, academic achievement, school regulation, academic performance, and life satisfaction.

This study also investigated the relationship between the dimensions of courage and the QoL and social health. The relevant results suggested a positive and significant relationship in this regard. Besides, the dimensions of courage could explain social health and QoL. These findings were in line with those of Seligman and Patterson's studies, in which 6 virtues were introduced in exploring different cultures and religions; wisdom, courage, humanity, justice, temperance, and transcendence. They categorized them and defined strengths and capabilities for each of these 6 virtues. Seligman also declared that happiness is created by recognizing and applying human strengths, capabilities, and fundamental talents in personal, occupational, familial, and social relationships. In addition, when social varieties enhance more positive human relationships, and happier people and more satisfied people can be found. Individuals must recognize their capabilities and strengths and use them in different situations, resulting in improved QoL in various aspects, such as work, enter- tainment, and parenting [21]. It is worth noting that the results of no studies were found inconsistent with the results of the present study. Finally, the properties that could improve the level of biopsychological health and social regulation were highly relevant; courage is one of them. A study limitation was the lack of investigating the psychometric properties of courage in a larger sample of students. Furthermore, applying this scale, in other instances, could enrich it further. It is also suggested that the youth's courage and character strengths and their academic achievement be considered, which may result in promoting their healthy behaviors, QoL, and life satisfaction.

The psychometric properties of the psychological virtue of courage have been proved and could be used in future research studies. Moreover, there was a significant relationship between courage, QoL, and social health aspects. The investigated questionnaire was developed according to the calculated psychometric parameters. Accordingly, the researchers could use it in academic situations to evaluate the virtue of courage from the Islamic perspective.

\section{Ethical Considerations}

\section{Compliance with ethical guidelines}

All ethical principles were considered in this research. The study participants were informed about the purpose of the research and its implementation stages and signed the informed consent. They were also assured about the confidentiality of their information. Moreover, they were allowed to leave the study whenever they wished, and if desired, the results of the research would be available to them. This article was the result of a doctoral dissertation of Psychology of the Islamic Azad University of Sari and had the code of ethics IR.IAU.SARI. REC.1397.39 from the Ethics Committee of the Islamic Azad University of Sari.

\section{Funding}

This research received no specific grant from funding agencies in the public, commercial, or not-for-profit sectors.

\section{Authors' contributions}

All authors contributed equally in preparing all parts of the research. 


\section{Conflict of interest}

The authors declared no conflicts of interest.

\section{References}

[1] Flinchbaugh CL, Moore EW, Chang YK, May DR. Student wellbeing interventions: The effects of stress management techniques and gratitude journaling in the management education classroom. Journal of Management Education. 2012; 36(2):191-219. [DOI:10.1177/1052562911430062]

[2] Avey JB, Luthans F, Hannah ST, Sweetman D, Peterson C. Impact of employees' character strengths of wisdom on stress and creative performance. Human Resource Management Journal. 2012; 22(2):165-81. [DOI:10.1111/j.1748-8583.2010.00157.x]

[3] Lomas T, Ivtzan I. Second wave positive psychology: Exploring the positive-negative dialectics of wellbeing. Journal of Happiness Studies. 2016; 17(4):1753-68. [DOI:10.1007/s10902-015-9668-y]

[4] Darabi M, Macaskill A, Reidy L. Stress among UK academics: Identifying who copes best. Journal of Further and Higher Education. 2017; 41(3):393-412. [DOI:10.1080/0309877X.2015.1117598]

[5] Duan W, Ho SM, Siu BP, Li T, Zhang Y. Role of virtues and perceived life stress in affecting psychological symptoms among Chinese college students. Journal of American College Health. 2015; 63(1):32 9. [DOI:10.1080/07448481.2014.963109] [PMID]

[6] 11. Furnham A, Ahmetoglu G. Personality, ideology, intelligence, and self-rated strengths. Psychology. 2014; 5(08):908. [DOI:10.4236/psych.2014.58102]

[7] Gander F, Proyer RT, Ruch W, Wyss T. The good character at work: An initial study on the contribution of character strengths in identifying healthy and unhealthy work-related behavior and experience patterns. International Archives of Occupational and Environmental Health. 2012; 85(8):895-904. [DOI:10.1007/s00420-012-0736-x] [PMID]

[8] Hannah ST, Sweeney PJ, Lester PB. Toward a courageous mindset: The subjective act and experience of courage. The Journal of Positive Psychology. 2007; 2(2):129-35. [DOI:10.1080/17439760701228854]

[9] Harzer C, Ruch W. The relationships of character strengths with coping, work-related stress, and job satisfaction. Frontiers in Psychology. 2015; 6:165. [DOI:10.3389/fpsyg.2015.00165] [PMID] [PMCID]

[10] Jablin FM. Courage and courageous communication among leaders and followers in groups, organizations, and communities. Management Communication Quarterly. 2006; 20(1):94-110. [DOI:10.1177/0893318906288483]

[11] Joseph S, Linley PA. Positive adjustment to threatening events: An organismic valuing theory of growth through adversity. Review of General Psychology. 2005; 9(3):262-80. [DOI:10.1037/10892680.9.3.262]

[12] Kristjánsson K. Positive psychology, happiness, and virtue: The troublesome conceptual issues. Review of General Psychology. 2010; 14(4):296. [DOI:10.1037/a0020781]
[13] Macdonald C, Bore M, Munro D. Values in action scale and the Big 5: An empirical indication of structure. Journal of Research in Personality. 2008; 42(4):787-99. [DOI:10.1016/j.jrp.2007.10.003]

[14] McCullough ME, Snyder CR. Classical sources of human strength: Revisiting an old home and building a new one. Journal of Social and Clinical Psychology. 2000; 19(1):1-0. [DOI:10.1521/jscp.2000.19.1.1]

[15] Glisky EL, Marquine MJ. Semantic and self-referential processing of positive and negative trait adjectives in older adults. Memory. 2009; 17(2):144-57. [DOI:10.1080/09658210802077405] [PMID] [PMCID]

[16] Park N, Peterson C, Seligman ME. Strengths of character and wellbeing. Journal of social and Clinical Psychology. 2004; 23(5):603-19. [DOI:10.1521/jscp.23.5.603.50748]

[17] Gillham J, Adams-Deutsch Z, Werner J, Reivich K, Coulter-Heind V, Linkins M, Winder B, Peterson C, Park N, Abenavoli R, Contero A. Character strengths predict subjective wellbeing during adolescence. The Journal of Positive Psychology. 2011; 6(1):31-44. [DOI:10 $.1080 / 17439760.2010 .536773$

[18] Gustems-Carnicer J, Calderón C. Virtues and character strengths related to approach coping strategies of college students. Social Psychology of Education. 2016; 19(1):77-95. [DOI:10.1007/s11218015-9305-y]

[19] Coghlan A, Filo K. Bringing personal character strengths into the production of the leisure experience. Leisure Sciences. 2016 38(2):100-17. [DOI:10.1080/01490400.2015.1087355]

[20] Shryack J, Steger M, Krueger R, Kallie C. The Structure of Virtue. Personality and Individual Differences. 2010; 48:714-9. [DOI:10.1016/j.paid.2010.01.007]

[21] Zhang Y, Chen M. Character strengths, strengths use, future self-continuity and subjective wellbeing among Chinese university students. Frontiers in psychology. 2018; 9:1040. [DOI:10.3389/fpsyg.2018.01040] [PMID] [PMCID]

[22] Yong AG, Pearce S. A beginner's guide to factor analysis: Focusing on exploratory factor analysis. Tutorials in quantitative methods for psychology. 2013; 9(2):79-94. [DOI:10.20982/tqmp.09.2.p079]

[23] Snell DL, Siegert RJ, Surgenor LJ, Dunn JA, Hooper GJ. Evaluating quality of life outcomes following joint replacement: psychometric evaluation of a short form of the WHOQOL-Bref. Quality of Life Research. 2016; 25(1):51-61. [DOI:10.1007/s11136-015-1044-1] [PMID]

[24] Karaś D, Cieciuch J, Keyes CL. The polish adaptation of the Menta Health Continuum-short form (MHC-SF). Personality and Individua Differences. 2014; 69:104-9. [DOI:10.1016/j.paid.2014.05.011] 
